\title{
Development of Solid-State Induction Modulators for High PRF Accelerators
}

\author{
H. Kirbie, S. Hawkins, B. Hickman, B. Lee, M. Newton, C. Ollis, \\ C. Brooksby, D. Gilbert, D. Longinotti, and E. Eubank
}

This paper was prepared for submittal to the Proceedings of the 10th IEEE Pulsed Power Conference

Albuquerque, NM

July 10-13, 1995

July 5,1995

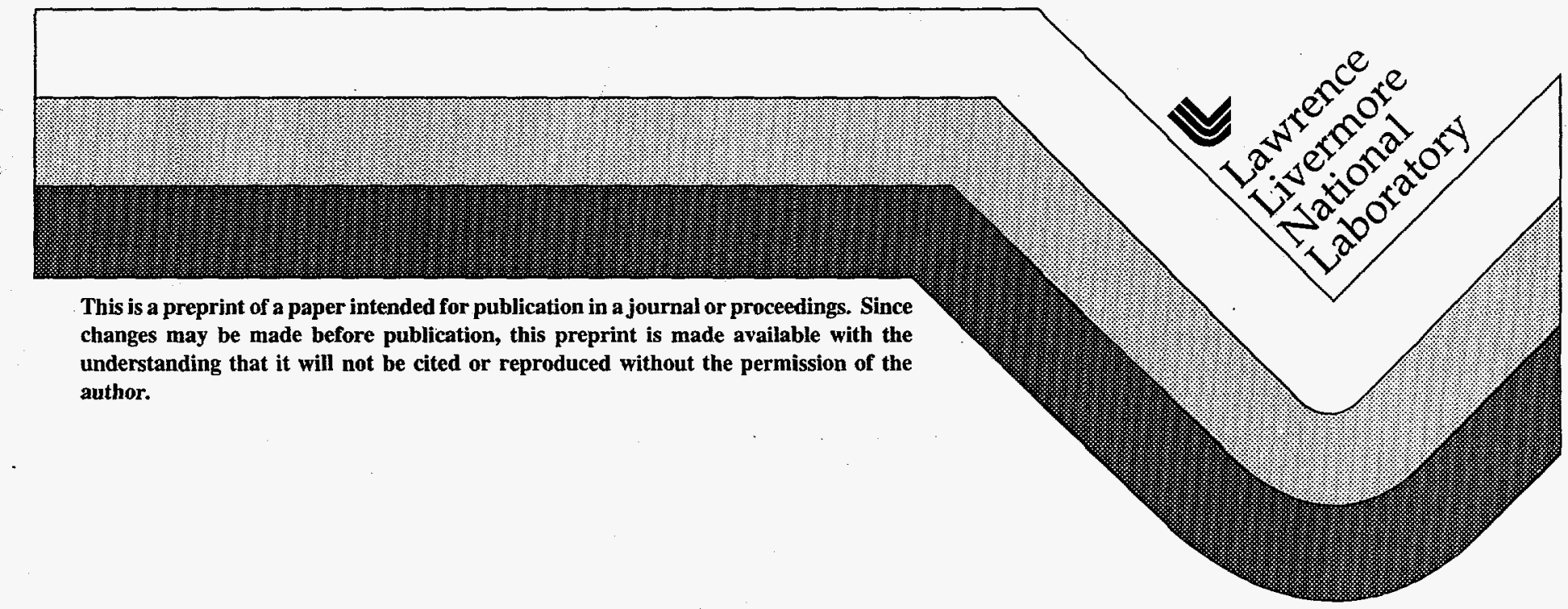




\section{DISCLAIMER}

Portions of this document may be illegible in electronic image products. Images are produced from the best available original document. 


\title{
DEVELOPMENT OF SOLID-STATE INDUCTION MODULATORS FOR HIGH PRF ACCELERATORS
}

\author{
H. Kirbie, S. Hawkins, B. Hickman, B. Lee, M. Newton, C. Ollis \\ Lawrence Livermore National Laboratory, Livermore, CA, 94550 \\ C. Brooksby, D. Gilbert, D. Longinotti \\ EG\&G Energy Measurements, Pleasanton, CA, 94558 \\ E. Eubank \\ University of Texas at Arlington, Arlington, TX, 76019
}

\begin{abstract}
Introduction
Researchers at the Lawrence Livermore National Laboratory (LLNL) and EG\&G Energy Measurements are developing a new solid-state power system for two proposed accelerators. One of the accelerators is a circular arrangement of induction cells called a recirculator. ${ }^{1}$ It is designed to accelerate heavy ions for an inertial fusion study that proposes to substitute heavy-ion beams for laser beams as the driver for fusion targets. ${ }^{2}$ The other accelerator is a linear induction accelerator for electron beams called the Advanced Radiographic Machine (ARM). This accelerator generates multiple bursts of $x$ rays for pulsed radiography by producing electron beams in rapid succession. Both accelerators require their induction cells to be pulsed at a very high repetition frequency (prf) for a short burst containing 5 to 15 pulses.

The recirculator has a pulse schedule that varies in pulse width from $1 \mu s$ to $400 \mathrm{~ns}$ and in prf from 50 to $150 \mathrm{kHz}$. The ARM accelerator has a pulse schedule that varies in pulse width from $1 \mu$ s to $200 \mathrm{~ns}$ and in prf from $150 \mathrm{kHz}$ to $1 \mathrm{MHz}$.
\end{abstract}

The need for complex pulse agility in these accelerators led us to examine solid-state switching components that have an on/off capability. The intrinsic speed of solid-state switching satisfies our high prf requirements, while the on/off switching action of some semiconductor devices enables us to select an arbitrary pulse width. To accommodate these requirements, we selected field effect transistors (FETs) as the preferred switching elements.

The same FET switching technology applies to both accelerators due to their similar pulse requirements. However, these two accelerators differ greatly in peak power and prf range. For example, the power system for the ARM accelerator must supply over $3 \mathrm{kA}$ of beam-current loading to a $150-\mathrm{kV}$ induction cell. Figure 1(a) shows the two induction-adder structures needed to achieve this high-power level. Each structure is composed of many small induction modulators that contribute $15 \mathrm{kV}$ per modulator toward the total cell voltage. For contrast, Fig. 1(b) shows only an induction accelerating cell without an external power source, indicating that the recirculator power system is contained within each cell. The recirculator cell supplies only $5 \mathrm{kV}$ to the ion beam per circulation and experiences very little beam-current loading.

For our research, two full-scale prototypes were built-a 5-kV induction recirculator cell and a single 15$\mathrm{kV}$ induction modulator for the ARM accelerator. We discuss the general network features that are common to both machines, followed by performance and modeling data.

\section{Circuits and Switches}

The recirculator cell and the ARM induction modulator use the same basic circuit, shown in Fig. 2(a). Closing the switch $\mathrm{S} 1$ connects the energy storage capacitor $\mathrm{C} 1$ directly across the induction core $\mathrm{L} 1$. The voltage VC1 accelerates the beam, but it also drives a steadily increasing magnetization current, shown in Fig. 2(b). Once the acceleration pulse ends, S1 opens and the cell current begins to decrease. The sudden change in cell current results in a rapid voltage reversal on $\mathrm{L} 1$, which continues in the positive direction until the diode D1 is forward biased. The reset capacitor is precharged to the voltage VC2, which dictates the rate of cell current decay and helps to restore the magnetic flux density back to its original value. Additional details concerning the circuit and its operation may be found in earlier publications. 3,4 

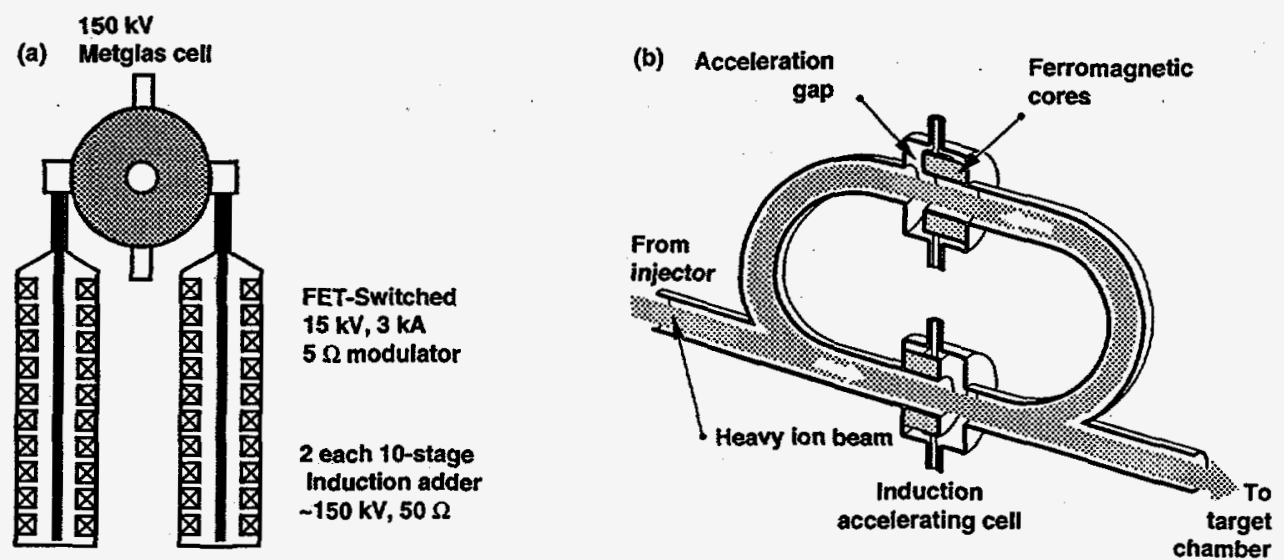

Figure 1. (a) ARM induction accelerator cell flanked by two induction-adder structures. (b) Illustration of a two-cell ion recirculator.

Table I lists the component values and maximum design voltages from Fig. 2(a) for both machines and provides design parameters as well.

\section{Performance Tests}

The performance tests demonstrate the operating ranges of prf and pulse agility for both machines while examining several operational issues, including: opening and closing processes for the FETs, power delivery to external loads, and the system's stability during a burst.

\section{Induction Recirculator Cell}

Figure 3(a) shows the recirculator cell. The cylindrical assembly houses an induction core surrounded by capacitors (not visible) and is positioned on an insulated horizontal shaft. There are four switching modules attached to the core assembly and each module contains eight, 1-kV circuit cards. Figure 3(b) shows a rear view of one switching module.

Figure 4 compares single-pulse voltage and current data with simulations. The top row of simulated data was obtained using the Micro-Cap $I V^{6}$ circuit analysis program for a 1- $\mu$ s pulse with initial capacitor voltages of $5 \mathrm{kV}$ and $900 \mathrm{~V}$. The bottom row of experimental data shows the acceleration voltage
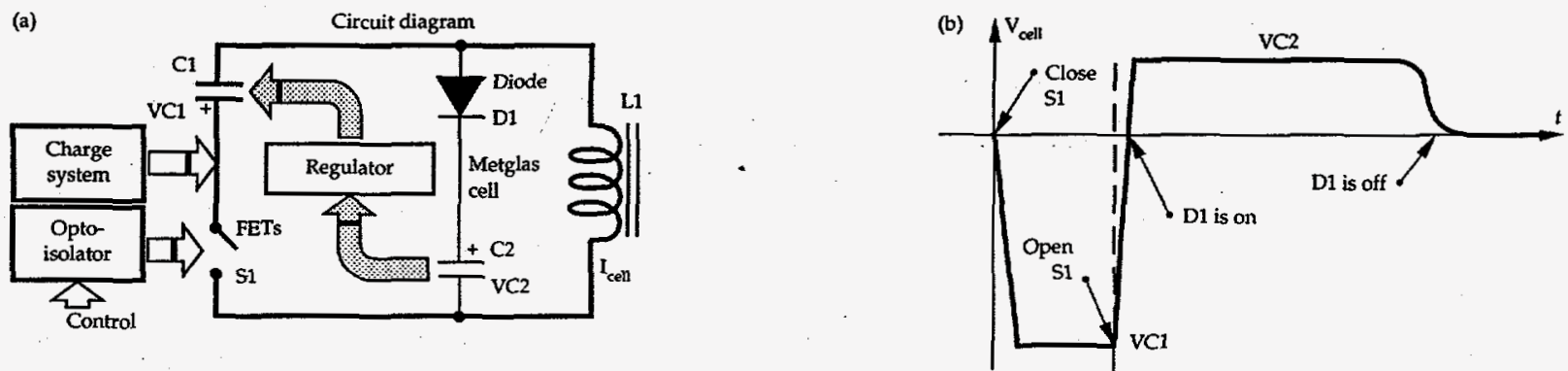

30-00-0295-0487pb01

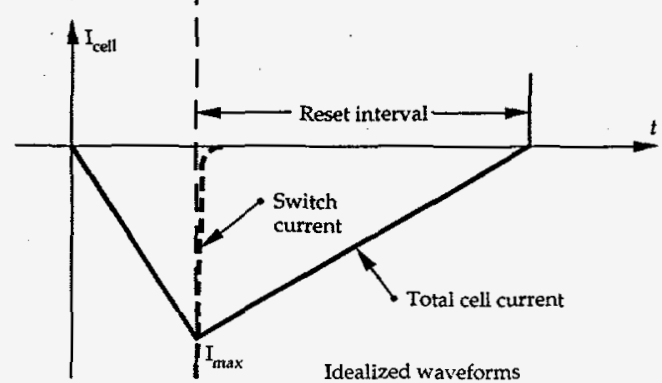

Figure 2. (a) Simplified circuit diagrams for the recirculator cell and ARM modulator. (b) Idealized current and voltage waveforms. 
Table I. Comparison of component values and design parameters for the recirculator cell and ARM modulator.

\begin{tabular}{lcc}
\hline Components/Parameters & Recirculator Cell & ARM Modulator \\
\hline Components and Voltages: & & \\
C1 & $6 \mu \mathrm{F}$ & $15.7 \mu \mathrm{F}$ \\
VC1 & $5 \mathrm{kV}$ & $15 \mathrm{kV}$ \\
C2 & $136 \mu \mathrm{F}$ & $15.7 \mu \mathrm{F}$ \\
VC2 & $900 \mathrm{~V}$ & $5 \mathrm{kV}$ \\
L1 & $18 \mu \mathrm{H}$ & $38 \mu \mathrm{H}$ \\
Design Parameters: & & \\
Max. current & $800 \mathrm{~A}$ & $3 \mathrm{kA}$ \\
Pulse range & $200 \mathrm{~ns}-1 \mu \mathrm{ss}$ & $200 \mathrm{~ns}-1 \mu \mathrm{s}$ \\
PRF range & $250 \mathrm{kHz}-150 \mathrm{kHz}$ & $1 \mathrm{MHz}-150 \mathrm{kHz}$ \\
Max. energy stored & $75 \mathrm{~J}$ & $1.8 \mathrm{~kJ}$ \\
No. of FETs & 128 & 1,152 \\
Metglas 5 core material & $2605 \mathrm{~S}-3 \mathrm{~A}$ & $2605 \mathrm{~S}-3 \mathrm{~A}$ \\
Machine o.d. & $83.8 \mathrm{~cm}$ & $94 \mathrm{~cm}$ \\
Approx. weight & $80 \mathrm{~kg}$ & $220 \mathrm{~kg}$ \\
\hline
\end{tabular}

detail and the switch current flowing though each module. Eight current signals are necessary to describe the total machine current, because each module is equipped with two current-viewing resistors (CVRs). The total switch current depicted in the simulation can be compared with a measured value by multiplying any of the four current signals by eight. The four measured currents, shown in Fig. 4, are a single CVR signal from each module, indicating an equal division of current.

The recirculator cell is designed for high prf burst operation and great pulse agility. The operational factors that define the prf limits within a burst are the capacitor charge voltages and the desired pulse width. An extreme test of prf performance is obtained with a combination of the minimum operating pulse width $(200 \mathrm{~ns})$ and the maximum accelerating and reset voltages $(5 \mathrm{kV}$ and $900 \mathrm{~V})$. Figure 5(a)

(a)

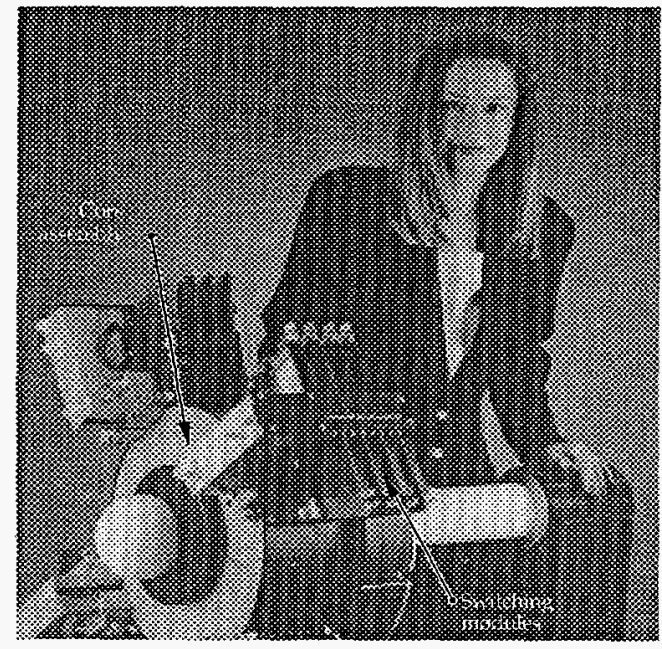

30-00-0295-0490pb02 (b)

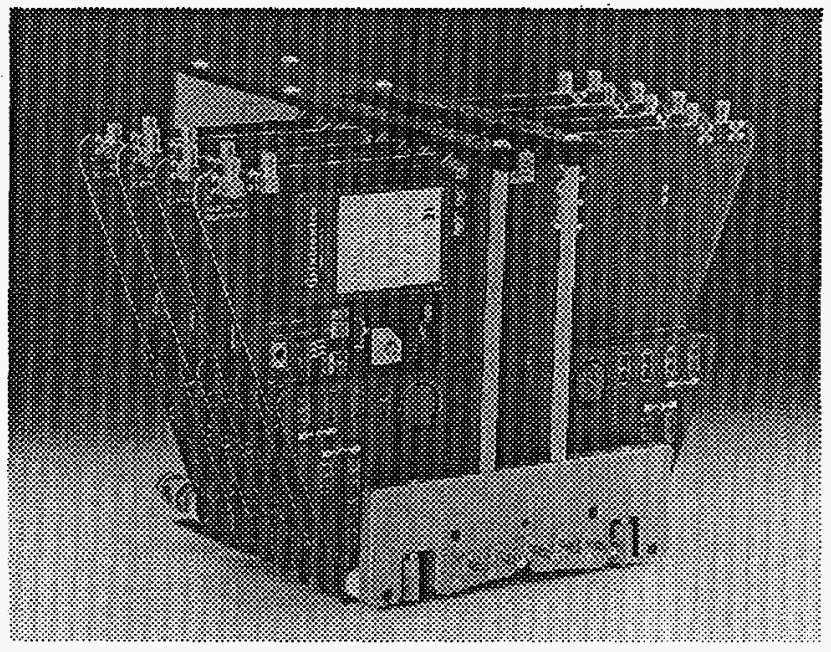

30-00-0795-1716pb02

Figure 3. (a) Photograph illustrating the close integration between the switching modules and the induction core assembly. (b) Photograph of a single switching module. 

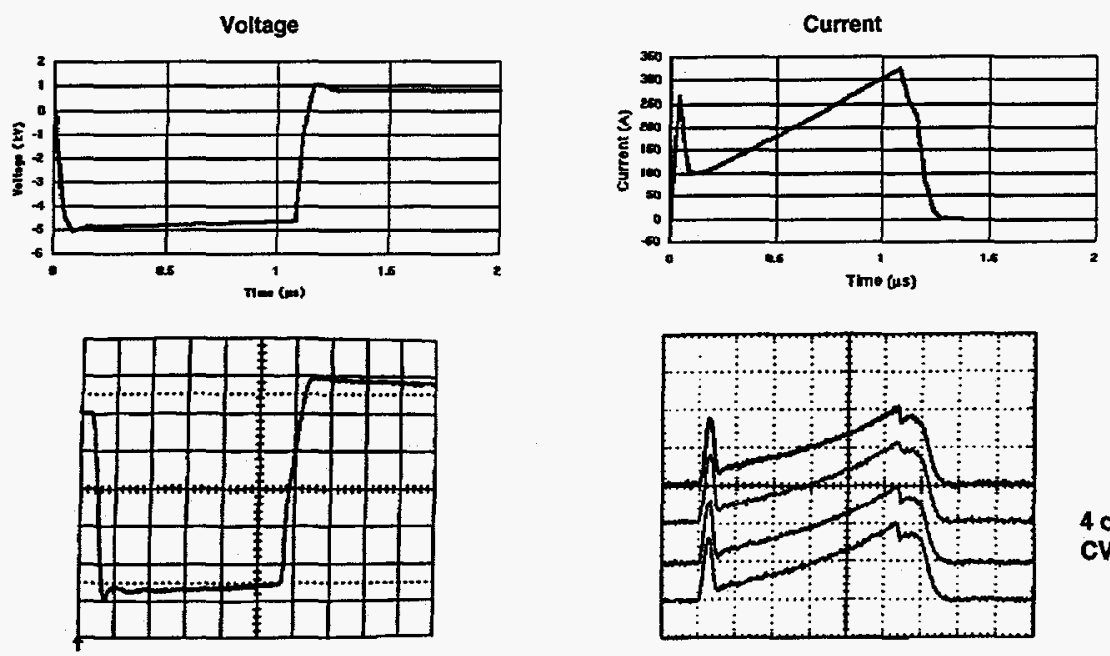

1 kV/div. 200 ns/div.

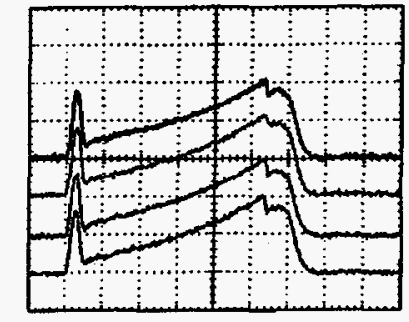

20 Addiv. 200 ns/div.
4 of 8

CVR Signals

Figure 4. Comparison of a network simulation (top) with measured data (bottom).

shows that five, $200-\mathrm{ns}$ pulses will recur at $250-\mathrm{kHz}$ rate under a maximum prf performance test. Figure 5(b) illustrates the machine's pulse agility by altering the pulse width and pulse separation from pulse to pulse. For this test, the capacitor voltages remain at their maximum values but the pulse width changes from $200 \mathrm{~ns}$ for the first pulse to $1 \mu$ s for the fifth pulse.

\section{ARM Induction Modulator}

Figure 6(a) is a photograph of the ARM induction modulator. An induction core is located behind the central plate and supported on an insulated horizontal shaft. Eight modules surround the core. Each module houses a capacitor bank inside a fiberglass outer shell and a switching package beneath the shell and against the core's outer surface. Figure 6(b) shows the detail of a single-switch package, where 24, $1-\mathrm{kV}$ circuit cards are racked together and are interconnected by conducting washers.

The testing program for the ARM modulator began by characterizing the full machine at a low voltage $(5 \mathrm{kV})$ to obtain network models and operating experience with various loads. Initial tests at high voltage were conducted with only two modules at a time to avoid unnecessary risk to the entire modulator. The final tests included eight modules at high voltage.

Figure 7 compares single-pulse voltage and current data with Micro-Cap IV simulations. The top row of simulated data was obtained for a 1- $\mu$ s pulse width with initial capacitor voltages of $5 \mathrm{kV}$ and $1.5 \mathrm{kV}$. The bottom row of experimental data shows the acceleration voltage detail and the switch currents from two modules for the same initial conditions. In contrast to the recirculator, each module is equipped with one CVR, but eight current signals are still necessary to measure the total machine current.

(a)

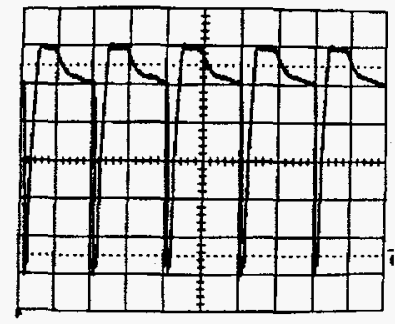

$1 \mathrm{kV} / \mathrm{div} .2 \mu \mathrm{s} / \mathrm{div}$. (b)

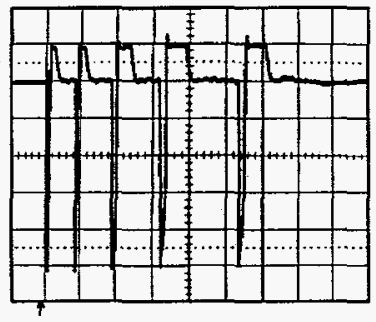

$1 \mathrm{kV} / \mathrm{div} .10 \mu \mathrm{s} / \mathrm{div}$.

Figure 5. (a) Five-pulse burst of 200-ns pulses at a mazimum rate of $250 \mathrm{kHz}$. (b) Five-pulse burst of variable pulses to show machine agility. 
(a)

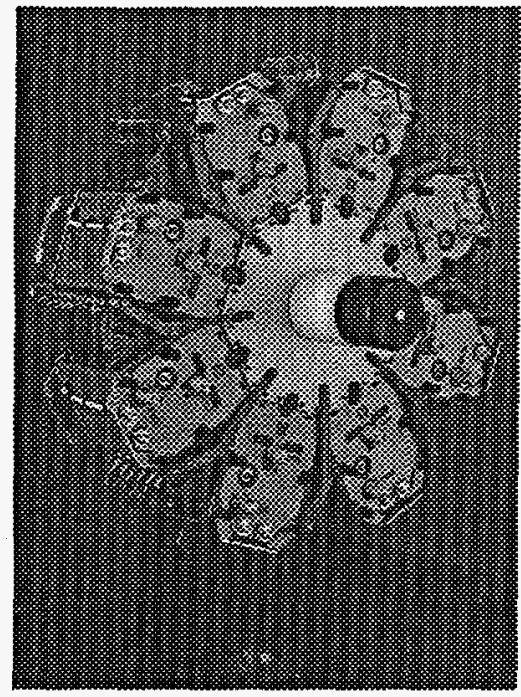

30-00-0795-1716pb02 (b)

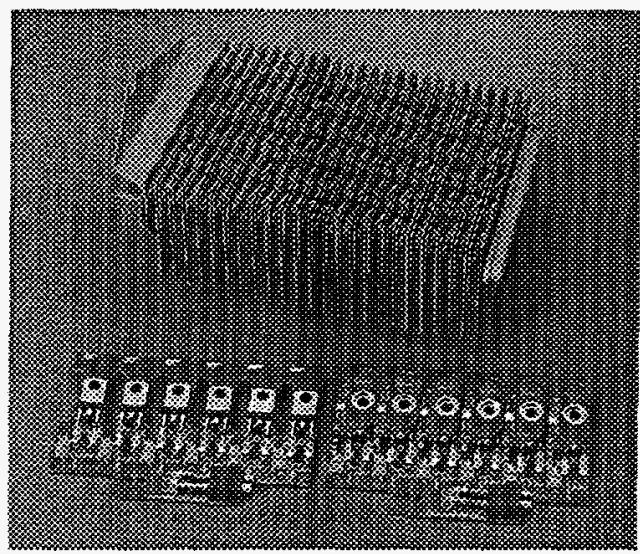

30-00-0795-1716pb01

Figure 6. (a) Photograph of the ARM induction modulator. (b) Photograph of a single-switch package with two individual circuit cards.

Consequently, the total switch current depicted in the simulation can be compared with a measured value by multiplying either of the two current signals by eight.

Figure 8 shows the results of another single-pulse, $5-\mathrm{kV}$ test, where we apply a long pulse until the induction core saturates. Figure 8(a) shows the core voltage collapse, which is matched by a sudden rise in switch current shown in Fig. 8(b). The flat portion of the switch current in Fig 8(b) indicates the current is limited by the FET array impedance to a total of $3 \mathrm{kA}$. The current falls to zero because the FETs are commanded to open at the end of the applied pulse.

Figure 9 shows two 5-pulse bursts of 200-ns pulses but under very different test conditions. Figure 9(a) is a $350-\mathrm{kHz}$ burst from all eight modules charged to $5.3 \mathrm{kV}$. In this case, the modulator is driving a load impedance consisting of a $5-\Omega$ resistive load in parallel with a $40-\mu \mathrm{H}$ inductor. The resistors simulate loading from an electron beam and are diode-coupled to conduct current only during the accelerating
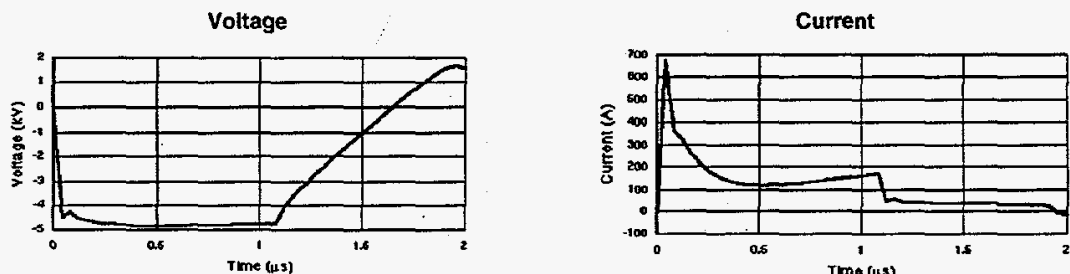

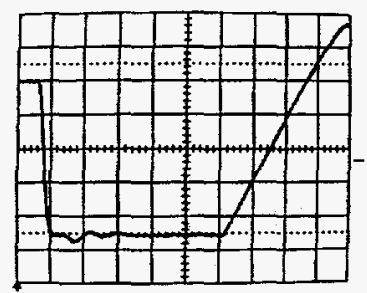

$1 \mathrm{kV} / \mathrm{div} .200 \mathrm{~ns} / \mathrm{div}$.

$30-00-0795-1737$

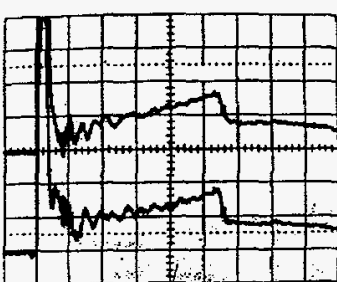

10 A/div. 200 ns/div.
2 of 8

CVR Signals

Figure 7. Comparison of a network simulation (top) with measured data (bottom). 
(a)

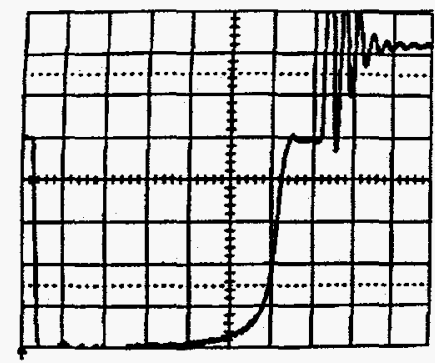

$1 \mathrm{kV} / \mathrm{div} .500 \mathrm{~ns} / \mathrm{div}$. (b)

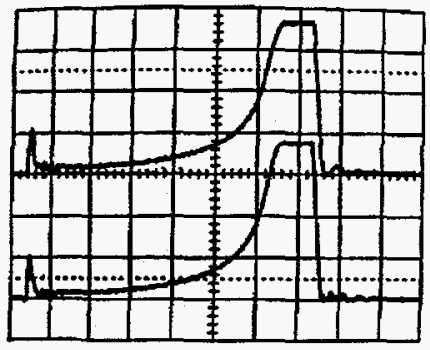

100 Adiv. 500 ns/div.

Figure 8. Response of the modulator to long pulses. (a) Core voltage and (b) switch current for two modules.

pulse. The 40- $\mu \mathrm{H}$ inductor simulates the ARM accelerating cell and conducts current throughout the entire pulse. Each 200-ns pulse in Fig. 9(a) generates $1.1 \mathrm{kA}$ of total switch current. Figure 9 (b) is a 620$\mathrm{kHz}$ burst from two modules charged to $14 \mathrm{kV}$. In this case, the modulator is unloaded so each 200-ns pulse generates only $75 \mathrm{~A}$ of total switch current. Other module pairs were tested to their full $15-\mathrm{kV}$ working voltage.

\section{Summary}

To further enhance our understanding of accelerator designs, we tested solid-state power sources at LLNL. The prototypes are similar in their use of FET switching technology and basic circuit design; however, they differ in size and power. Test results indicate that agile, high-prf pulses can be generated by both prototypes while providing power to external loads for short bursts.

\section{Acknowledgments}

We wish to acknowledge the electronic and mechanical fabrication contributions by the EG\&G personnel at the ATLAS facilities in Las Vegas, Nevada. In particular, the recent efforts of Bill Bellow and Ken Brose are appreciated. We also recognize the contributions by employees of Raytheon Corp. at the Nevada Test Site. Specifically, we thank Rob Saethre for his detailed analysis of our optical systems.

This work was performed under the auspices of the U.S. Department of Energy by the Lawrence Livermore National Laboratory under contract number W-7405-ENG-48.

(a)

Eight Module

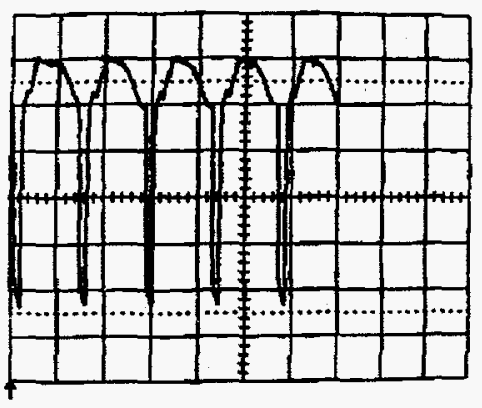

$1 \mathrm{kV} / \mathrm{div} .2 \mu \mathrm{s} / \mathrm{div}$. (b)

Two Modules

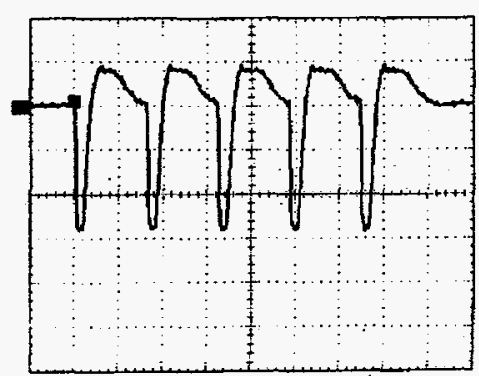

$5 \mathrm{kV} / \mathrm{div} .1 \mu \mathrm{s} / \mathrm{div}$.
$14 \mathrm{kV}$

Figure 9. Five-pulse burst data for two test conditions. (a) Maximum prf test at $5 \mathrm{kV}$ to $350 \mathrm{kHz}$. (b) Maximum prf test at $14 \mathrm{kV}$ to $620 \mathrm{kHz}$. 


\section{References}

1. J. J. Barnard, "Study of Recirculating Induction Accelerators as Drivers for Heavy Ion Fusion," Lawrence Livermore National Laboratory, Livermore, CA, UCRL-LR-108095 (September, 1991).

2. D. J. Dudziak, W. W. Saylor, and W. B. Hermannsfeldt, Fusion Technology 13(2), 207 (February, 1988).

3. H. C. Kirbie, et al., "Evolution of High-Repetition-Rate Induction Accelerators through Advancements in Switching,"Proceedings of the 1992 Linear Accelerator Conference, Ottawa, Ontario, Canada, August 24-28, 1992, p. 595.

4. H. C. Kirbie, et al., "A FET-Switch Induction Accelerator Cell," Proceedings of the 9th IEEE PulsedPower Conference, Albuquerque, NM, 1993, p. 415.

5. Metglas-a family of amorphous alloy ribbons manufactured by Allied-Signal Corporation, Metglas Products Division, 6 Eastmans Road, Parsippany, NJ, 07054.

6. Micro-Cap IV is an electronic circuit analysis program published by Spectrum, 1021 South Wolfe Road, Sunnyvale, CA, 94086. 